This item was submitted to Loughborough's Research Repository by the author.

Items in Figshare are protected by copyright, with all rights reserved, unless otherwise indicated.

\title{
Qualitative interviews in psychology: problems and possibilities
}

PLEASE CITE THE PUBLISHED VERSION

http://dx.doi.org/10.1191/1478088705qp045oa

PUBLISHER

Routledge (@ Taylor \& Francis) / @ Edward Arnold (Publishers) Ltd

VERSION

AM (Accepted Manuscript)

LICENCE

CC BY-NC-ND 4.0

REPOSITORY RECORD

Potter, Jonathan, and Alexa Hepburn. 2019. "Qualitative Interviews in Psychology: Problems and Possibilities". figshare. https://hdl.handle.net/2134/15020. 
This item was submitted to Loughborough's Institutional Repository (https://dspace.lboro.ac.uk/) by the author and is made available under the following Creative Commons Licence conditions.

\section{creative
commons}

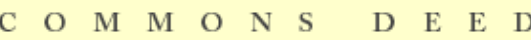

Attribution-NonCommercial-NoDerivs 2.5

You are free:

- to copy, distribute, display, and perform the work

Under the following conditions:

Attribution. You must attribute the work in the manner specified b the author or licensor.

Noncommercial. You may not use this work for commercial purposes.

No Derivative Works. You may not alter, transform, or build upon this work.

- For any reuse or distribution, you must make clear to others the license terms of this work.

- Any of these conditions can be waived if you get permission from the copyright holder.

Your fair use and other rights are in no way affected by the above.

This is a human-readable summary of the Leqal Code (the full license).

\section{Disclaimer 만}

For the full text of this licence, please go to: http://creativecommons.org/licenses/by-nc-nd/2.5/ 


\section{QUALITATIVE INTERVIEWS IN PSYCHOLOGY PROBLEMS AND PROSPECTS}

\section{Jonathan Potter* \& Alexa Hepburn}

Discourse and Rhetoric Group

Department of Social Sciences

Loughborough University

Loughborough

Leicestershire, LE11 3TU
Email: J.A.Potter@lboro.ac.uk

Email: A.Hepburn@lboro.ac.uk

Tel: 01509223384

Tel: 01509223876

Fax: 01509223944

* For correspondence.

Keywords: qualitative interviews, discursive psychology, footing, stake and interest, transcription, research agenda, cognitivism

\section{Published as:}

Potter, J. \& Hepburn, A. (2005). Qualitative interviews in psychology: problems and possibilities, Qualitative research in Psychology, 2, 281-307.

We would like to thank audience members at departmental seminars in the London School of Economics, February 2004, and the University of Rome, La Sapienza, July 2004, for helpful comments on an earlier version of this paper. The original idea arose in a conversation with Sandra Jovchelovitch and Caroline Howarth. The paper has greatly benefited from comments by Susan Speer and Elizabeth Stokoe. 


\title{
QUALITATIVE INTERVIEWS IN PSYCHOLOGY
}

\author{
PROBLEMS AND POSSIBILITIES
}

\begin{abstract}
This paper distinguishes a series of contingent and necessary problems that arise in the design, conduct, analysis and reporting of open-ended or conversational qualitative interviews in psychological research. Contingent problems in the reporting of interviews include: (1) the deletion of the interviewer; (2) the conventions of representation of interaction; (3) the specificity of analytic observations; (4) the unavailability of the interview set-up; (5) the failure to consider interviews as interaction. Necessary problems include: (1) the flooding of the interview with social science agendas and categories; (2) the complex and varying footing positions of interviewer and interviewee; (3) the orientations to stake and interest on the part of the interviewer and interviewee; (4) the reproduction of cognitivism. The paper ends with two kinds of recommendation. First, we argue that interviews should be studied as an interactional object, and that study should feed back into the design, conduct and analysis of interviews so that they can be used more effectively in cases where they are the most appropriate data gathering tools. Second, these problems with open-ended interviews highlight a range of specific virtues of basing analysis on naturalistic materials. Reasons for moving away from the use of interviews for many research questions are described.
\end{abstract}


This paper is about the use of open-ended or conversational interviews in psychological research. It has a series of aims. First it will briefly document the centrality of the qualitative interview in contemporary psychology and describe some of the research that has been carried out on the conduct of social research methods. Second it will highlight some shortcomings in the way interview research has often been reported that can be reasonably easily rectified. Third it will identify a range of features of qualitative interview interaction that are endemic and inescapable, and note some of the difficulties they raise for the satisfactory analysis of interviews. Fourth, it will consider the implications of this discussion for improvements in the use of open-ended interviews. Finally, it will consider some of the advantages of working with naturalistic materials that are specifically highlighted by considering the endemic features of open-ended interviews. In effect this discussion of interviews will highlight some more systematic features of naturalistic materials.

The paper will take a schematic approach. The aim is to pull together a broad range of issues and clarify their implication for understanding interviews. Each of these issues is worthy of much fuller treatment but the intention here is to capture the broader implications of the combination of these issues. Likewise, there will not be much attempt to show the generality of these problems - however, we expect researchers who work with interviews to recognise them without difficulty. Moreover, it would be invidious to pick out particular pieces of research, or particular methodological expositions, for comment. We have chosen instead to illustrate our points with an example from our own interview research. Our approach will be argumentative but constructive. The aim is to challenge the taken-forgranted position of the open-ended interviews as the method of choice in modern qualitative psychology. We will draw heavily on the resources of discursive psychology (Edwards, 1997, Edwards \& Potter, 1992; Potter \& Edwards, 2001) and conversation analysis (Sacks, 1992; Hutchby \& Wooffitt, 1998) to develop the argument. Nevertheless, the points are intended to have a much broader relevance than specifically to those researchers with a discourse or conversational interest. We will also draw on an increasing body of research (mostly from outside of psychology) that has started to topicalise the research interview and the activities that make it up, to raise questions about the interpretations of interviews and suggest ways for developing this research instrument (prominent examples include Baker, 2001; Lee \& Roth, 2004; Rapley, 2001; van der Berg, 2003; Widdicombe \& Wooffitt, 1995). The immediate aim is to generate debate about the role of qualitative interviews in psychology. The ultimate aim is to improve the quality of interviews and their targeting at particular research problems. The ideal would be much less interview research, but much better interview research.

Before we start a note on terminology. The focus is on interviews where participants are not required to merely choose from a selected set of response categories, or tick boxes, to rate vignettes, or to engage in some other 'structured' procedure. That is, these are interviews where participants are answering questions verbally and there is some attempt to capture their words (perhaps using notes, but more likely recordings and transcriptions). Such interviews have been called conversational, active, qualitative, open-ended or even sometimes (confusingly) semi-structured. An interview of this kind will typically be guided by a schedule of topics or questions, although their order in the interview may vary and interviewers are likely to depart from the schedule and use a variety of follow up questions (or comments, responses, or some other contributions). We are deliberately not attempting to develop a more specific definition at this point or to make further distinctions between different kinds of qualitative interview. See Kvale (1996), Mischler (1996), Fontana \& Frey (2000) and Warren (2001) for detailed discussions from a range of perspectives from across the social sciences. We will refer to the interviews of this kind simply as interviews from now 
on in the paper. Many of the issues raised here have broader relevance to social science focus groups, social surveys and other techniques for data generation and approaches to analysis. However, for clarity we will restrict our focus here to interviews.

\section{The interview in contemporary qualitative psychology}

There are many ways of documenting the central role that interviews play in contemporary qualitative psychology. For brevity, we have chosen to do this by highlighting the content of two excellent recent books that offer collections how-to-do-it chapters on qualitative research in psychology: Camic et al., (2003) and Smith (2003). In effect, these are the US and the European state-of-the-art collections. The US volume is published through the American Psychological Association (their first foray into qualitative methods) and Sage, a major publisher of qualitative research in psychology, published the European version.

There is a core set of perspectives represented in each book that are shared across the two volumes, and provide an indication of what might be considered standard in contemporary qualitative work. The thing we wish to note is the relation between the broad psychological perspective, the object of study (broadly speaking), and the technique for data generation (often just called 'the method'). For clarity we have laid this out in Table 1.

\section{Table 1 about here}

The point of this sketchy and somewhat rhetorical summary, of course, is that despite the highly varied topics that these different perspectives focus on, when it comes to generating materials to study they all have the qualitative interview (with the exception of discourse analysis and discursive psychology, of which more below) as the approach of choice. Moreover, if we consider the way interviews are described in these chapters mostly they are not only the technique of choice but also the choice to do interviews is taken-forgranted. There is very little explicit justification for the use of interviews and their appropriateness for the relevant object of study. This sense of interviews as the natural way to do non-experimental, non-questionnaire and non-survey work in psychology is one of the things this paper is designed to dissipate.

\section{Reservations and research studies}

Ethnomethodologists and conversation analysts have been sceptical about the use of interviews since the inception of those perspectives in the 1960s. However, although some important studies were done concerning the operation of research methods (often of a more structured kind) by Garfinkel (1967) and Cicourel $(1964,1974)$ the main reasons for scepticism were simply that they had found more interesting and fruitful alternatives in the study of peoples' organized practices (conversational or otherwise) in natural settings. Nevertheless, some classic ethnomethodological work, notably Garfinkel's (1967) 'Agnes' transexuality study, was based on interviews.

Qualitative researchers in sociology have considered a range of difficulties with the research interview. Silverman (2001) provides and excellent summary of problems in using interviews to do social research, focusing in detail on 'positivist approaches', which take interviews as a source of facts, and 'emotionalist approaches' that take interviews as a pathway to participants' authentic experiences (see also ten Have, 2004). For the most part, these critiques are not based on systematic research into what goes on in interviews, nor have they been directed at, or picked up by, researchers working within psychology. 
There is a growing literature that uses ethnomethodology, conversation analysis and/or discursive psychology to study the operation of methods in practice. The most studied topic here has been the standardized survey interview. Work on standardized surveys from an interactional perspective was stimulated by Suchman and Jordan (1990), who highlighted the failure of survey researchers to appreciate the centrality of interaction in administration surveys and the consequences for the achievement of standardization. They argued that survey researchers would need to respond much more flexibly to the contingencies of natural conversation if anything approaching standardization was to be achieved. This tradition was continued by others and has evolved into substantial body of work (Houtkoop-Steenstra, 1995, 1996, 1997; Maynard \& Schaeffer, 1997, 2000; Schaeffer \& Maynard, 1996). More recently research has focused on the administration of questionnaires (Antaki, 1999; Antaki and Rapley, 1996; Antaki, Houtkoop-Steenstra, Rapley, 2000; Rapley and Antaki, 1996) the organization of interaction in social science and market research focus groups (Myers, 1998; Myers \& Macnaghten, 1999; Puchta \& Potter, 1999, 2002, 2004; Puchta, Potter \& Wolff, in press) and the administration of psychological tests (Marlaire \& Maynard, 1990; Schegloff, 1999).

For some time discourse analysts have highlighted the significance of the interactional nature of interviews (Potter \& Mulkay, 1985; Potter \& Wetherell, 1995). Widdicombe \& Wooffitt (1995) in their well-known study of talk about youth subcultures develop a major critique of the ability of interviews to attend to the complicated categorization practices that are involved in them. However, they are less focused on how these are a function of the specifically interview features of the material. Rapley (2001), Lee and Roth (2004), and some contributions to van der Berg et al., (2003) have focused on the relationship between the interactional organization and research tasks. We will draw on this work as well as some of this other literature as we go along. Some of our points will build on observations in Antaki, et al., (2003). However, our goal is less descriptive and analytic and more focused on using the apparatus of CA, DP and ethnomethodology to highlight some important and largely overlooked problems with interviews.

\section{Part 1: Contingent Problems}

We will break our discussion into two parts: contingent problems and necessary problems. The rationale for this distinction is to separate out problems with interviews that are contingent in the sense that they are not a necessary feature of doing interview research, but could be (relatively easily) fixed, or at least attended to. The second part will focus on some problems that are necessary (endemic and inescapable) to the enterprise of researching with interviews. We will start with five contingent problems: (1) the deletion of the interviewer; (2) the conventions of representation of interaction; (3) the specificity of observations; (4) the unavailability of the interview set-up; (5) the failure to consider interviews as interaction. Our points here are not original. All of them have been made in one form or another before, although often informally rather than formally. However, the point here is to develop them, illustrate them, and collect them together as a package and note that researchers are still, regularly, fail to take them seriously.

The paper will focus on a concrete example to illustrate these points and the ones that are to come. As indicated above, it would be invidious to select one study from another researcher to illustrate problems that are very widely shared across interview research. Instead, we will offer a reconstruction (with actual materials) of some generic features of the presentation and interpretation of interview research. This comes from a research project written up in Hepburn (1995, 1997a, b, 2000; Hepburn \& Brown, 2001). From the original interview corpus we selected haphazardly one interview and (roughly) one question and 
answer sequence. The points we will make are intended to be generic to interviews so findable just about anywhere. We expect that interview researchers will have no difficulty in recognising them in their own work and that of others.

\section{The deletion of the interviewer}

This point has been made in a range of discussions of interview research, usually in terms of the interviewee's talk being taken out of context (see Bowers, 1988 for a reflexively applied example). We wish to further clarify what this means in practice. The following extract shows the sequence rendered in a style common to a wide range of contemporary qualitative research (again, we are not wishing to pick on particular examples, however, illustrations can be found in Camic et al. (2003) and Smith (2003)).

Extract One Teacher:

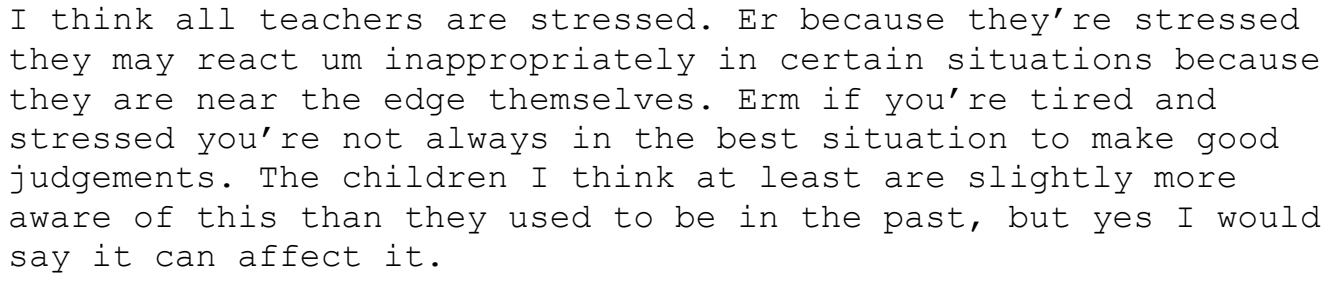

This extract uses a conventional orthographic representation of talk. This constructs it to look like a form of playscript. The talk is rendered into sentences with conventional textual punctuation. The first point to note here is the deletion of the interviewer. This works in two ways. Most obviously the interviewer is not represented in the extract. We only have talk listed as from the Teacher. Yet more subtly the talk is rendered as an abstract statement pronouncing on the nature of teachers and the effects of stress rather than a specific answer to a specific question put by a specific interviewer.

This is clarified if we start to fill in more of what is missing using the same orthographic style. We have rendered the additions in a lighter font to show the kind of talk that is commonly omitted.

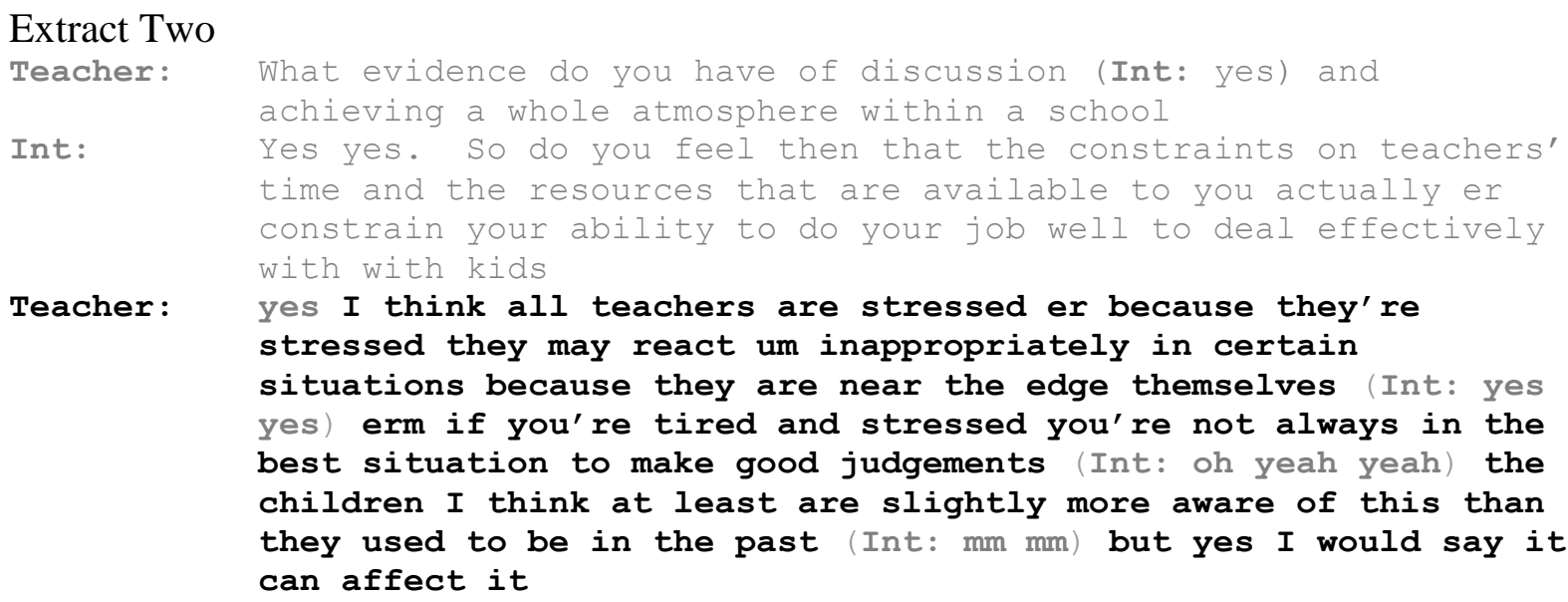

This includes more of the interaction. It gives some representation of the interviewer's question and various 'interjections'. Yet it is still rendered as playscript. The precise actions going on here are hard to pin down because of the representation of interaction that is offered here. 


\section{The conventions of representation of interaction}

For some thirty years conversation analysts have been developing styles of transcription that capture elements of talk that are interactionally relevant. Gail Jefferson has been the major figure in these developments. See, for example, Jefferson (1985) and summaries in ten Have (1999) and Hutchby \& Wooffitt (1998) and conventions summarized the appendix. The extract below shows the interview sequence represented using Jeffersonian transcription.

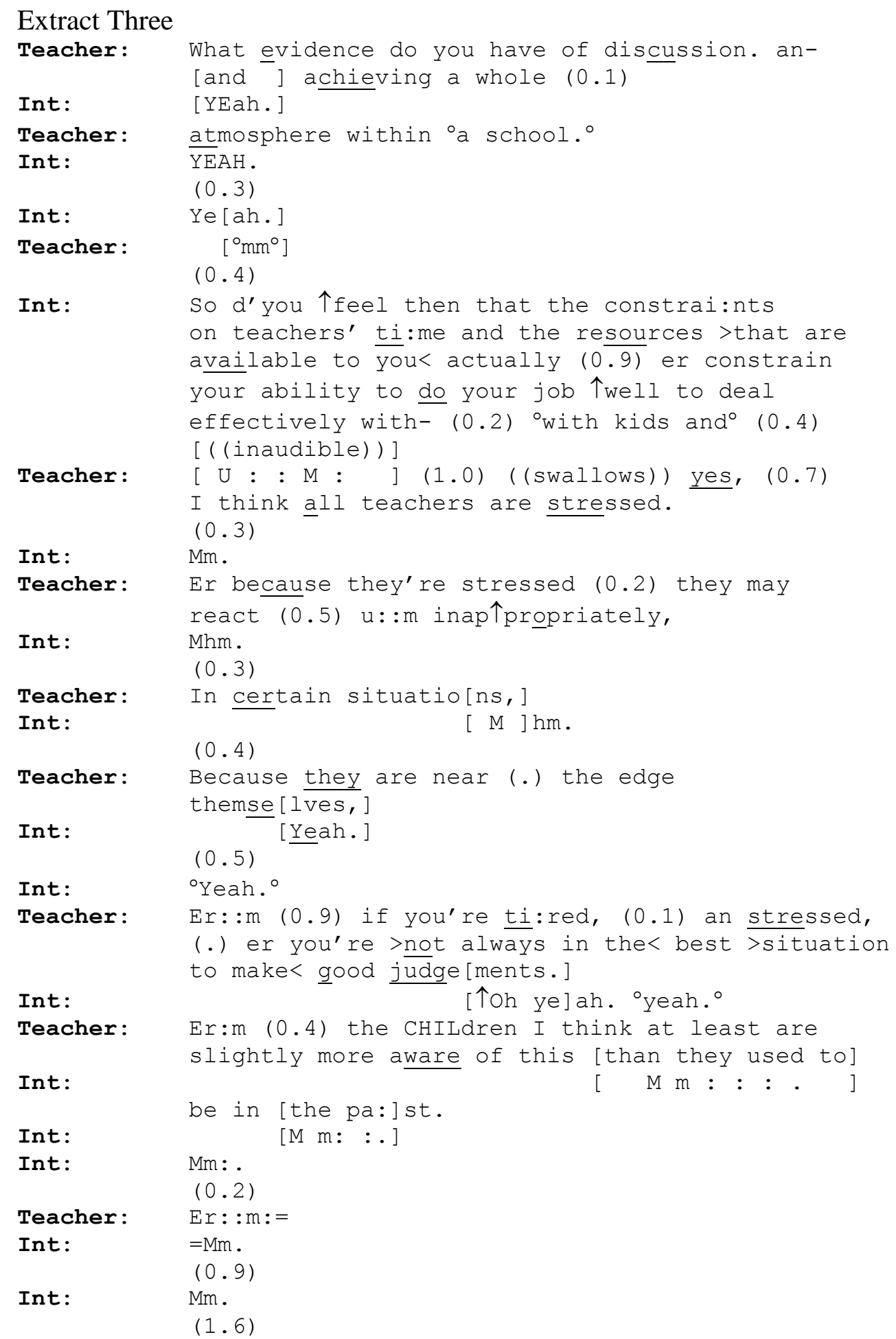


(An audio record of this interaction is available through the Loughborough Discourse and Rhetoric Group web site at http://www.lboro.ac.uk/departments/ss/centres/dargindex.htm)

Even in this brief extract we are able to highlight a wide range of hearable, and therefore potentially conversationally live, features that are missed in the standard orthographic version (see Rapley, 2001, for a further illustration of this kind). Again, we are not suggesting that all of these features are absent from all reports of interview research, but we did not have any difficulty finding a range of current publications where such features are missed. Examples are easily identified in the Smith and Camic volumes. We have summarized them in Table 2.

Table 2 about here

More broadly our fictionalised typical transcript in Extract One misses potentially consequential interviewer actions such as the acknowledgement tokens (Clayman \& Heritage, 2002) on lines 19, 22 and 25; it also misses the news receipt and agreeing second assessment (Heritage, 1984; Pomerantz, 1984) on line 35. Give the significance of such elements to the development of this talk we suggest that they ought to be represented in the transcript and therefore made available to readers.

There are real tensions here with good arguments in each direction. In the past it has not been uncommon to advocate a kind of Jefferson Lite for interview research, a form of transcription capturing the words and some of the grosser elements of stress and intonation, but leaving pauses untimed and not attempting to capture more subtle elements such as closing and continuing intonation, latching, and so on. Potter \& Wetherell (1987) advocates just this, and has often been cited since then as a warrant for this practice (see Willig, 2001 for a recent psychological example). Poland (2001) makes much the same kind of argument. Researchers against using fuller transcript may build the case that for the analysis of the broader ideological content of talk, where the key thing is the words, categories and repertoires used, the representation of features of speech delivery will only get in the way. The 'minutiae' of conversation will distract from the 'broader' ideological organization of the talk. There is some power to this observation. However, we find the alternative argument more compelling. This is that the analysis of broader patterns and ideological talk should be able to deal with the specifics of what is going on in the talk rather than simply a reconstructed, simplified and distorted version of it. Not only should it be able to deal with this, but it will be most effective and persuasive if it does deal with it. Most pertinently for those with a focus on ideological issues, the full Jeffersonian representation of talk makes most apparent the jointly constructed, socially engaged nature of what is going on, including the close dependence of what the interviewee says on the interviewer's question (and vice versa) in all its specifics.

Note that this is not just an issue for the researchers conducting the analysis and their own theoretical and analytic proclivities and allegiances. Insofar as the evaluation of the work is a communal endeavour for journal referees and readers there is a strong argument that the researchers should provided a form of transcription of talk that will allow readers to make a full evaluation rather than one that may already embed their own theoretical assumptions within it. To some extent developments in technology and the web distribution of materials will make these problems less acute. As we have noted, the interaction we are working with is available on the web. But there is still work to do. 
None of this is to underestimate the effort involved here. While a professional service might be able to produce playscript interview transcript at a time ratio of 4-6 hours of work per hour of interview, even a skilled Jeffersonian transcriber is unlikely to better a ratio of 20 to 1 . And this will go down with recording quality, quiet speakers, language and accent complexities and so on. If the researcher's overall time for a study stays constant they will need to make sacrifices somewhere else, probably in sample size.

\section{Global Observations}

This point refers to the way in which analytic observations, of whatever kind, are linked to the interview transcript. Similar points are made in Antaki, et al. (2003) with respect to the ways researchers can underanalyse materials. Our observations are designed to compliment theirs. Here the issue is how an observation is made explicit or how a claim about the interview is substantiated. In the conventional orthographic representation common in interview research is it often not clear what specific elements of the talk are being referred to. This is partly because this form of transcript collapses together (potentially) large numbers of different sorts of conversational elements.

For example, if we consider Extract One we can see that a range of different elements of the interviewee's answer, which is constructed interactionally with the interviewer, are collapsed together (with the interviewer contributions absent). The separate lines for the interviewer and interviewee in the Extract Three version allow the turn organization of the interview to be clarified and clearer reference to be made to each. The line numbers allow a further specificity of reference to be achieved. It is not uncommon in contemporary qualitative interview papers in psychology to find a large block of text reproducing interviewee's talk, with some observations made about it that are very hard to clearly link to specific elements of the talk.

Looked at another way, the challenge in analysis is to show how your claims can account for the specifics of the talk, not just its broad themes. The block-of-text form of representation does not allow those specifics and their relation to the analysis to be clearly seen.

\section{The unavailability of the interview set up}

The set up of the interview is potentially critical in at least two, and most likely more ways. First, what category have the participants been recruited under? Are they taking part in the research on the basis that they are a 'lesbian mother', an 'adolescent male', a 'recreational drug user', or something less explicit? Interview research typically recruits participants under categories of this kind. After all, this is a feature of proper attention to sampling. How are these categories constructed in the various parts of the recruitment (including the introduction to the research, ethics procedures, administrative arrangements, and so on)? Second, what is the task understanding offered to the participant? This involves questions such as: what are they told that the interview will be about, what it will be for, and what the task of the interviewee will be?

These are complicated issues. Not only are full records of these things not kept, but there are (good) ethical reasons for not collecting such records before full consent procedures have been fulfilled. Moreover, it is hard to do adequately informative consent procedures before a range of important details about the task and the reasons for recruitment have been described. Nevertheless, given the importance of these (and other) features some attempt at recording and representing what went on seems to be required. For example, textual materials relating to recruitment could be included in the write up and some attempt could be made to at least gloss the interaction between the participant and researcher prior to the 
interview. As far as possible, when the actual interview takes place the recording could be started as early as possible, so that the researchers gloss on the interview and its goals is captured on tape and can be reproduced in materials.

This is not an issue that has received much discussion in the past. The point here is to signal both its neglect and importance and to start, tentatively, to indicate some ways in which it could be attended to.

\section{The failure to consider interviews as interaction}

These first four problems amount, taken together, to a failure to treat interviews as an interaction. This is ironic given the agreement, within those approaches to psychology using qualitative interviews that appreciating their interactional nature is essential for their analysis (Gubrium \& Holstein, 2001). The problem is in following the implications of this insight through into the design, practice, and representation of interviews. The point here is that the recognition that interviews are interactional has consequences for interview research. For the points we have made above the consequences are all addressable in a relatively straightforward manner (although, as we have noted, there are principled arguments to be made with some of our suggestions). That is why we have called these contingent points they are problems that are more or less fixable by changing the way interview talk is reported and represented in terms of the form of the transcript and what sections of interviews are extracted and by including further information about the interaction that went on with the participants as they were inducted into the study. Their contingency is apparent by noting that the best interview studies do indeed concur with these features.

Our proposal is that research that is reporting interviews should include at least the following elements. (1) At minimum it should include the relevant interview question(s). This is probably the topic initial question as well as any follow-ups or 'prompts'. This in itself might not be sufficient, but will allow at least an initial consideration of the relation between the question construction and the answer. (2) The interview extracts should be transcribed to a level that allows interactional features to be appreciated even if interactional features are not the topic of the study. That is, they should be transcribed in more than Jefferson Lite (or equivalent). (3) The interview extracts should be presented in such a way, probably using line numbers and short lines that allow discrete connections to be made between elements of talk and analytic interpretations. (4) The report should include information about how participants were approached, under what categories, with what interview tasks. Some current interview studies include some of these elements; few include them all. Further research and argument in this area might well suggest more features for inclusion.

\section{Part 2: Necessary Problems}

So far we have discussed problems with interviews for which there is a relatively straightforward practical solution. For the second half of the paper we will identify some problems that are less easily dealt with. They represent a set of problems that can be highlighted by considering interview interaction from a conversation analytic and discursive psychological perspective. These are problems that generate interpretational difficulties in the analysis of interview talk. And a further problem is that they are additive or even multiplicative. That is, each can generative uncertainly about how it relates to the others. That is not to say that sensitive and skilled analysis cannot develop important claims (from a range of perspectives) based on interviews. But it highlights some of the elements that such analysis will need to grapple with. Previously this has been done more of less implicitly - in future it may need to be more explicit. 
We will focus on four issues: (1) the flooding of the interview with social science agendas and categories; (2) the complex and varying footing positions of interviewer and interviewee; (3) the possible stake and interest of interviewer and interviewee; (4) a drag toward cognitive and individual explanations. We will take them in turn.

\section{Issue 1: Flooding the interview with a social science agenda and categories}

By social science (or psychological) agenda we are referring loosely to the set of concerns and orientations that are central for the researcher. Some of these may be quite explicit and reflect the specific research questions that are a focus of the research. Others may be extremely inexplicit and reflect the disciplinary embeddedness of the research enterprise. This might include the factors and variables approach characteristic of modern empirical psychology, the various theoretical frames that interview researchers use, the assumptions about what a person can know about her or his own practice and so on. The list is a potentially long one.

The social science agenda is bound up with (although goes beyond) the categories that are used. These include the various more or less technical terms and descriptions that appear in interview questions and interview responses. This is a rather complicated topic as it may be quite hard to judge what terms are social scientific and what not. They are rarely likely to be as explicit as the following example:

Please describe a time in your life when you experienced internalized homophobia (Giorgi \& Giorgi, 2003: 263).

However, as social representations researchers, Foucaultians and others have argued, everyday talk can involve a range of 'sedimentations' of earlier 'theoretical' notions as the languages of psychoanalysis, Marxism, symbolic interactionism and so on become parts of people's everyday conversational currency.

Let us consider the interview question from Extract Three again.

\section{Extract Four}

Int:

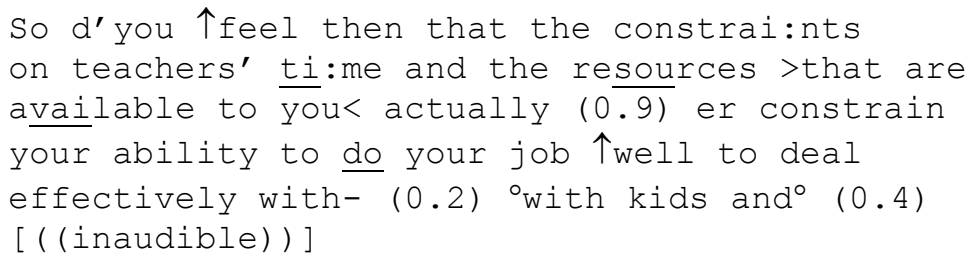

Let us start with a very basic observation. Although the question may appear rather casually developed, with its hesitations (e.g. the delay and 'er' on line 12) and trailing off (the quiet on 14 and the inaudible elements on 15) it is nevertheless a recognisable type of social research question. Indeed, it is arguable that it is these 'casual' elements that, in part, constitute its social science features. For example, Puchta and Potter (2004) identify such features in market research focus groups as procedures for generating informality and managing potential epistemic asymmetries between interviewer and interviewee. And they note that uncompleted listings in multiple choice questions such as this can both provide candidate answers to model what the researcher expects and show that the listing offered does not exhaust answering possibilities. The point we are making here is that the question construction with its informality and candidate answer carefully (and appropriately) coaches the participant in the relevant social science agenda.

Although this question does not involve obviously recognisable technical terms (such as 'internalized homophobia') we can note the way that the question is constructed in terms of abstract processes and structures ('teachers' time' line 11, 'constraints' lines 10 and 12) 
and generic categories ('teachers' line 11, rather than, for example, specific teachers at specific schools). Looked at another way, this question is part of an abstract approach to social processes rather different from, say, a sequence of staff room troubles telling talk.

Note also that the social science agenda is not only developed in questions but also in various other types of interviewer turn. Take the following extract.

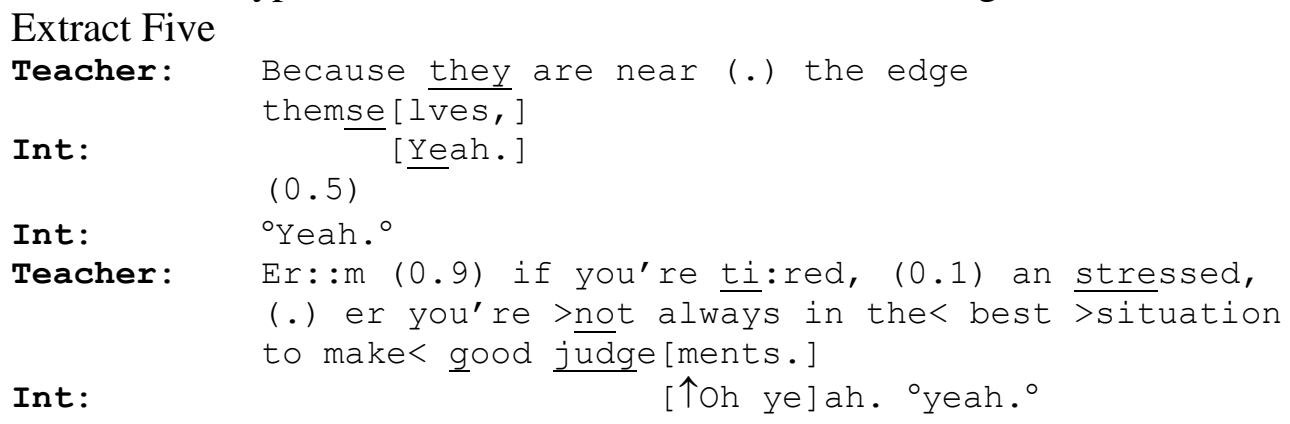

Note the difference between the acknowledgement tokens in 29 and 31 and the news receipt/agreement combination in 35. The elements of the teacher's talk in 27-28 and 32-34 are being receipted rather differently. Such differences could be consequential, and could reflect the researcher's agenda in different ways.

Issues about social science agenda and categories are difficult and hard to disentangle. What is social science and what is not, what are interviewer actions and what are not, are hard questions to answer. However, this is not to claim that they are unimportant. At its most basic these issues face us with the possibility that a piece of interview research is chasing its own tail, offering up its own agendas and categories and getting those same agendas and categories back in a refined or filtered or inverted form.

\section{Issue 2: Interviewer's and Interviewee's Footing}

The second necessary issue involves the footing or speaking position of the interviewer and interviewee. The notion of footing was introduced by Goffman (1981) to characterize conversational practices such as the current speaker reporting another's speech. He makes a contrast between the animator, the current speaker who is doing the talking, and the composer, the person who originally made up the words. And he notes that a further distinction is needed between the composer and origin of the viewpoint; for example, a political speechwriter may write words to express ideas for a leader. At the same time Goffman distinguished a range of different reception roles: e.g. addressed vs. unaddressed recipient, overhearer vs eavesdropper.

We can extend these footing categories to consider the different basis on which participants are speaking. For example, are they speaking as individuals or category members? And if a category member, what is the relevant category? Looked at another way, are they speaking as individuals with an institutional identity or as persons with their own unique and idiosyncratic preferences? This brings the apparatus of membership categorization analysis to bear on interviews (Baker, 2001, 2004). And as Pomerantz and Zempel (2003) show, other kinds of contextualizing devices are also available in interviews.

Let us first consider the talk of the interviewee. Note again the question she is asked, and focus this time on the categories that are used.

Extract Six

Int:

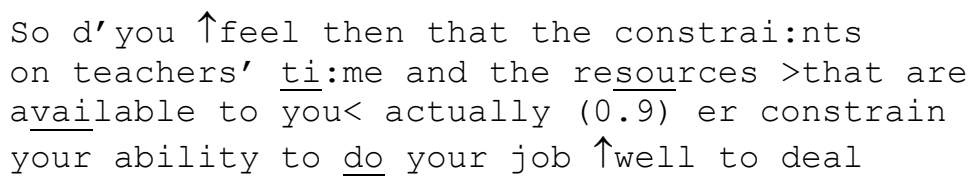




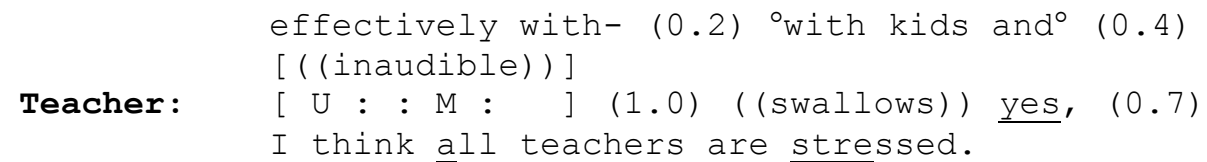

Note the way that the interviewee is addressed with a mix of direct personal terms ('you', 'your job' lines 12 and 13), but also as a category member ('teachers' time' line 11). This interviewee has been recruited as a category member (a teacher) and is being addressed as such. Her speaking position then for this interaction is as a teacher. Yet her 'personal' feelings are being asked about. And as we have already noted, in the transcript and research publication the interviewee is rendered using the category Teacher (see Billig, 1999; Watson, 2004, on this issue). The interviewee could exploit the contingency of answering questions to develop a distinction between constraints on her and on teachers generally. She is not forced to accept the terms of the question. However, this would involve a bit of work, as such a distinction is not projected by the question. She would have to roll back the multiple choice listing in lines 12-15 to do that. This could be just the kind of problem that generates the trouble at the start of the reply in line 16 (note the uncertainty marker, the long delay, and the swallow) although there are other plausible candidates.

Of course, one way to look at this is that the required psychological research task has been achieved - the participant is answering as a representative of the category that they have been recruited under. The problem, however, is that the precise category that the interviewee is speaking from can be quite hard to identify confidently; indeed, it may be profoundly ambiguous.

Now consider the footing of the Interviewer. Are they the addressed recipient? Or are they are conduit to some other recipient? For example, if this was a television news interview the interviewer and interviewee might both treat the overhearing audience as the proper recipient of the talk. This is shown, for example, by a lack of change of state markers (such as 'oh') in news interviewer talk. After all, they may be asking questions they already know the answer to, or are not interested in the answer to. The issue is not the news interviewer's change of knowledge state but how informed the audience has been (Clayman \& Heritage, 2002; Heritage \& Greatbatch, 1991).

The situation in qualitative interviews is complex - the interviewer addresses the interviewee. But are they who the talk is designed for? Sometimes the interview is set up with the interviewer presenting as strongly involved. At other times they may be presenting as neutral. There might be all kinds of delicacy in this set up when interviewing minority groups, or extremist groups such as fascists or racists (see Billig, 1977). Moreover, it is not just a matter of the overall set up at the start of the interview. Different kinds of interviewer turns can display different footing positions. Take the following from our target example:

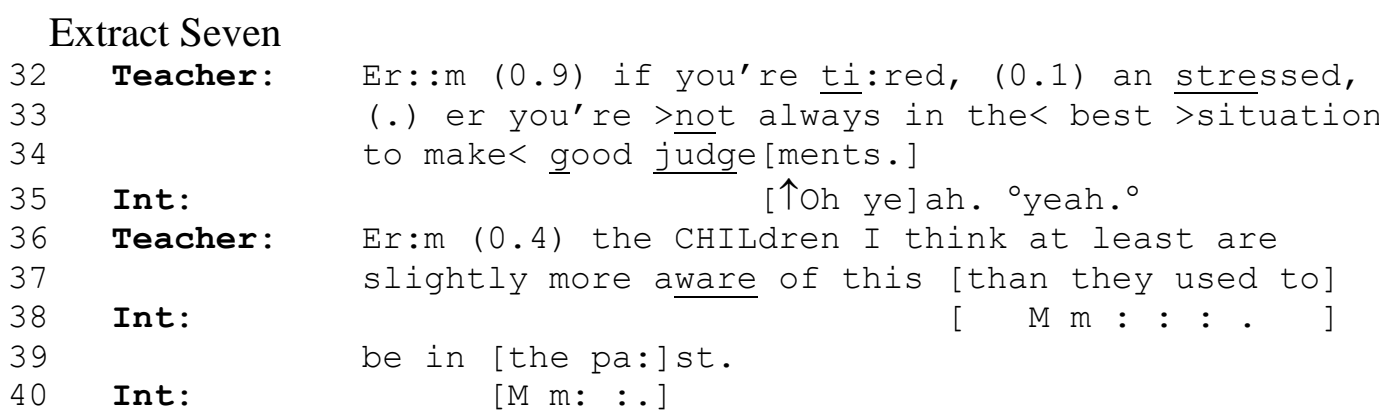

Note here the interviewer's news receipt and agreement in line 35 and the extended agreeing mms on 38 and 40. These turns show a different kind of involvement to that common in news interviews. They present a footing as a full recipient. The interviewer presents as not merely a conduit to the collection of knowledge but an active participant with their own 
knowledge and views. We can gloss this as active interviewing. But note that this is not a consistent feature of even this extract. Elsewhere the interviewer provides more sparse acknowledgement tokens (e.g. extract 3, lines 19, 22). The footing is variable.

The general point, then, is the footing for both interviewer and interviewee is potentially convoluted and variable. There are considerable complexities when addressing footing in interviews (see for example the debate: Leudar \& Antaki, 1996a, b; Potter, 1996). We have considered footing mainly in relation to the categories interviewee and interviewer; others have considered some of the more fine-grained footing shifts in interviewees talk (Ensink, 2003; Lee \& Roth, 2004; Wilkinson, 2000). In general, there is a major challenge here for anyone analysing interview material.

\section{Issue 3: Interviewer's and Interviewee's Stake and Interest}

One of the basic claims of discursive psychology is that in their interaction people orient to issues of stake and interest (Edwards \& Potter, 1992; Potter \& Edwards, 1990). That is, they may respond to what others say as based on particular interests, and they may manage issues of interest in their own talk. Note that this is not an attempt by discursive psychologists to understand what people say in terms of its interestedness; it is an attempt to take the issue of interestedness for participants as a topic.

In research interviews issues of stake and interest are both profound and complex. Let us take the interviewee to start with. As we have already noted, interviewees are typically recruited as members of a social category of some kind. There may well be an expectation that they have a stake in that category. Yet this is often combined with questions that treat the participant as a broadly neutral informant on their own practices. Nevertheless, these kinds of issues have often been a topic of analyses of qualitative interviews. Questions of how interview participants address and manage issues of stake and interest has been a thread running through a wide range of discursive psychological studies involving interviews. Issues of the interviewer's stake and interest have been less addressed.

It is routine, for example, for qualitative interviews to be conducted as parts of $\mathrm{PhD}$ projects where the interviewer and the researcher are combined in one person (a footing issue). It is also common (and appropriate) for $\mathrm{PhD}$ researchers to care deeply about the topics they are studying. The issue for us is not the interestedness or not of qualitative interviewers, but how issues of stake and interest are managed. One thing that is clearly absent from the interview analysed above is the sort of introductory element that is common in market research focus groups for example. This is a quote from near the start of a focus group where the moderator is describing what is going to happen in the group (see Puchta \& Potter, 2004 for further examples and analysis)

Extract Eight

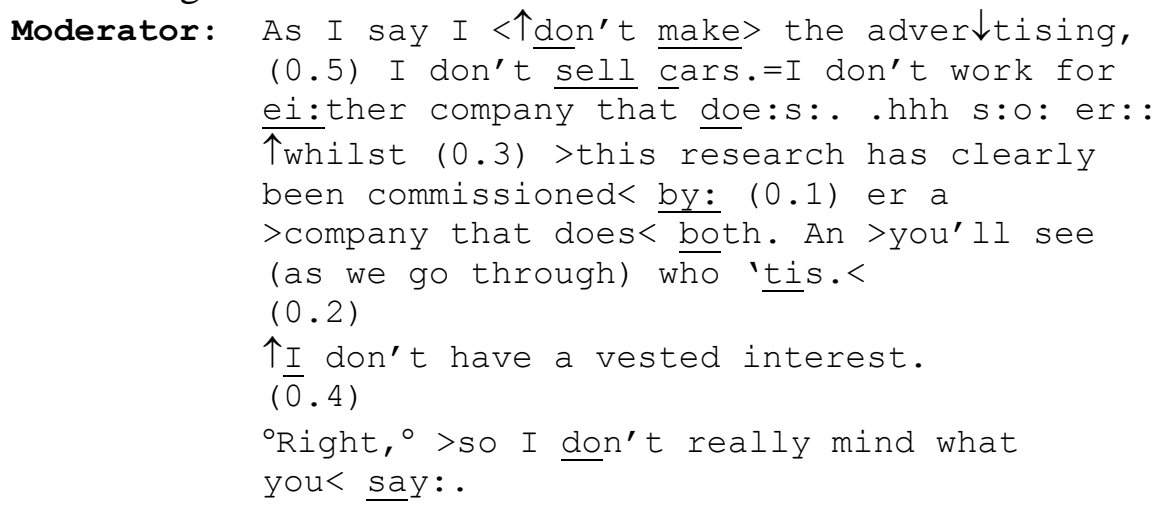


Note how much emphasis is placed on the independence of the moderator from the companies involved in producing either the advertising ideas or the cars themselves (lines 13 ). There is a very explicit construction of the advertising and car manufacturing interests, of the researchers' independence from these (repeated on line 9), and the relationship of what the participants say to the researcher's happiness (lines 11-12).

The kind of separation between the researcher and the direct concern with the topic is much less common in academic qualitative interview research. So such a strong emphasis on disinterest is probably not possible, whether desirable or not. Researchers can and do introduce issues of stake and interest explicitly in interviews, although our sense is that this happens more in the interview set up (where it is often therefore not available for considering its analytic implications, as we noted above). How such introductions relate to the trajectory of what goes on is an important, difficult and currently under researched topic.

As we have already noted with the example of footing, issues such as this are likely to vary across the interview. Issues of interest and involvement may come into play in different places in different ways. Let us just take the example of the previously quoted fragment. Extract Nine

Teacher: Er::m (0.9) if you're ti:red, (0.1) an stressed, (.) er you're >not always in the< best >situation to make< good judge [ments.]

Int: [个oh ye]ah. ${ }^{\circ}$ yeah. ${ }^{\circ}$

Teacher: Er:m (0.4) the CHILdren I think at least are slightly more aware of this [than they used to]

Int: be in [the pa:]st.

Int: $\quad[\mathrm{M} \mathrm{m}: \mathrm{:}:]$

Note again here the interviewer's displays of investment in the topic in lines 35, 38 and 40. Agreements (and disagreements, of course) can display broader alignments and interests in topics (cf. Koole, 2003). For the moment we will just note again that if we take this seriously it makes the process of interview analysis considerably more complicated than it is often presented. Again, our general point is that there is a profound complexity in interview material that is rarely explicitly addressed. To take it into account during analysis is a major challenge (for an example that highlights the subtlety of the challenge, see Edwards, 2003).

\section{Issue 4: Reproduction of Cognitivism}

For many interview researchers some kind of cognitive perspective will be entirely appropriate. Our point is not to directly question this desirability but to note how it can be an interactional product of the way interviews are conducted and a source of confusion. There are a number of potential facets here but we will concentrate on two: the privileging of conceptual rumination over action and the treatment of cognitive language as descriptive.

\section{Privileging conceptual rumination}

A basic feature of qualitative interviews is to treat the interviewee as a reporter on events, actions, social processes and structures, and cognitions. The point here is that this kind of explicit conceptual rumination is treated as providing a way into participants lives or social organizations or whatever the topic of the research project. This shows up in the way participants answer questions. Note the (at least apparently) abstract, syllogistic logic of the following:

Extract Ten

16 Teacher:

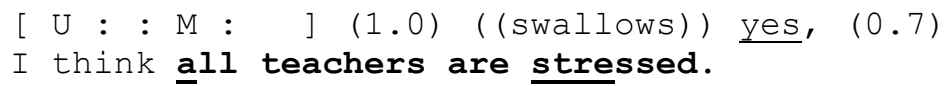


And note the way causal relationships are identified as the participant theorizes as a protosocial scientist.

Extract Eleven

Teacher:

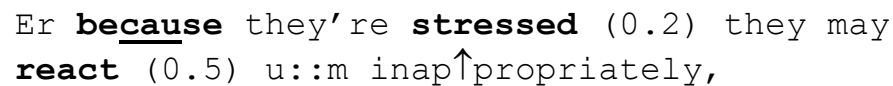

There is a lot more we could say about how these descriptions are put together. However, the basic point to note is that here the teacher is being asked as a teacher not to be a teacher but to formulate features of the lives of teachers and what causes them to act in particular ways. Again, this is not doing much more than restate the basic rationale often assumed when doing interviews. You ask people about what they do and think and they helpfully tell you about it. The point, however, is to highlight precisely the assumption that interviewees can helpfully tell you about social processes, causal relations and so on.

Of course, the most straightforward version of this assumption was criticised by early discourse analytic work (Gilbert \& Mulkay, 1984; Potter \& Mulkay, 1985; Potter \& Wetherell, 1987; Wetherell \& Potter, 1988). Partly on the basis of variability in interviewee talk, the argument was made for changing the focus to the activities done in interview talk and the resources used in that talk. A large amount of research has been done since this time (of varying quality). However, interview analysis of this kind is still challenging. In the first place it often requires the analyst to make difficult extrapolations from the kinds of actions done in the interview talk to the kinds of actions done elsewhere. In the second place the activities done in interviews are particularly complicated because of the sorts of agenda, footing, stake and interest issues that we have noted above. Moreover, it is likely that much of this discourse analytic work using interviews has underestimated the pervasiveness of interview identities and practices in its analysis, and it has been supported in this underestimation by a range of the contingent problems noted in the first section of the paper.

\section{Cognitive Language as Descriptive Language}

A second feature characteristic of qualitative interviews is the treatment of cognitive language. The focus on the practical role of cognitive terms has been a major topic of discursive psychology (see Edwards, 1997, for overview). More recently some work has considered the role of cognitive terminology in social research settings. For example, Puchta and Potter (2002, 2004; Myers, 2004; Potter \& Puchta, forthcoming) have considered the practical role of 'POBA' terminology; the use of terms such as Perceptions, Opinions, Beliefs and Attitudes (the acronym is from Henderson, 1991 although Puchta \& Potter, 2004, highlight a broader family of such terms). These studies have highlighted both the way that such notions are related to issues of accountability (important for generating answers) and how social research interaction is often organized to accomplish POBAs as objects within individuals.

In our current extract, for example, note the use of the POBA term 'feel' at in initial element of the topic-initial question.

Extract Twelve

Int: So $d^{\prime}$ you $\uparrow$ feel then that the constrai:nts

on teachers' ti:me and the resources >that are

In market research focus groups POBA constructed questions were used to head off both 'don't know' responses and to discourage participants from asking the moderator. The interactional logic of POBAs is that people are the best experts on their own POBAs and they should not be directly undermined by factual considerations. It seems likely that something very similar is going on in Extract Twelve. It would be too much of a digression to elaborate on these issues here (see Potter \& Puchta, forthcoming). Our point is that to fully understand the qualitative interview as an interaction we will need to pay attention to the practical and 
interactional role of cognitive terms and be very cautious about treating such terms as if they referred to psychological objects of some kind within individuals.

Similar sorts of issues arise with the interviewee's use of psychological or cognitive terminology. To take one example, the interviewee uses the term 'stressed' on three occasions in this sequence (lines 17, 20,32). Whatever referential role this term has, careful analysis will need to consider what it is being used to do in this sequence. For example, Hepburn \& Brown (2001) in an analysis of these interviews highlight some of the practical uses of stress talk in managing accountability and linking individual actions in with broader institutional roles and relationships. Our point again is that to fully understand what is going on in qualitative interviews researchers will need to be attentive to the practical role of psychological language.

\section{INTERVIEWS - PROBLEMS AND PROSPECTS}

We will organize this concluding section in two parts. First we will consider the implications of this paper for the use of qualitative interviews in social research. Second, we will discuss the relative virtues of work with records of naturalistic interaction.

\section{Qualitative Interviews}

We started by overviewing a set of contingent problems with the design and presentation of qualitative interviews: (1) the deletion of the interviewer; (2) the conventions of representation of interaction; (3) the specificity of observations; (4) the unavailability of the interview set-up; (5) the failure to consider interviews as interaction. Without attempting an extensive survey we have no doubt that readers can select just about any journal that regularly publishes psychological work based on qualitative interviews and find examples which display some or all of these problems. This is not surprising as even some of the "how to do it' manuals for research involving qualitative interviews in psychology show the same problems. Furthermore, as we noted some researchers have argued that these are not really shortcomings. However, our conclusion is that these are problems, and that qualitative research in psychology would in general be improved by correcting them. Moreover, research opting for alternative practices should justify precisely how and why it would be improved by, say, deleting the interviewer or using a more playscript reconstruction of talk.

The second set of problems we considered were ones that are a necessary part of doing interviews: (1) the flooding of the interview with social science agendas and categories; (2) the complex and varying footing positions of interviewer and interviewee; (3) the possible stake and interest of interviewer and interviewee; (4) the reproduction of cognitivism. These necessary problems are intimately connected to the contingent ones because they are often obscured by the common representational practices used in interview research. Our argument here is that none of these elements can be eliminated (issues of agendas, footing, interest, and so on will always be relevant to some extent) rather they present the interview researcher with particularly acute set of analytic problems. Whatever the analytic perspective, inferring things appropriately from interviews involves understanding what is going on in them interactionally, and that in turn involves the complex and demanding task of analysing the development of an implicit research agenda, identifying footing shifts, explicating orientations to stake and so on. As researchers with some expertise in interaction analysis we would like to emphasise that this is a challenging analytic requirement. Such analysis is rarely done with any degree of seriousness in current interview research, and where it is the analysis often highlights just how much the interviewee's talk is a product of specific features of the interview. Widdicombe and Wooffitt (1995) is one of the best exemplifications of this. 
Furthermore, these necessary problems highlight issues for the design and conduct of interviews. Interviewer introductions, questions, responses and so on have received surprisingly little systematic study (Rapley (2001) and some contributions to van den Berg et al, (2003) are the exceptions). Such study could start to tease out the way different kinds of social science agendas are established, the way footing shifts are marked and so on. Alternative ways of designing questions, for example, might offer up clearer routes to analysis. Moreover, what precisely is involved in the strand of work that has emphasised the limits of traditional 'neutral interviewing' and has pressed the case for 'active interviewing' (Gubrium \& Holstein, 2004) could be explicated. Closer analysis is likely to show up these categories are much too simple and that 'active interviewing' is made up of a range of different elements, often combined with elements that look more like 'neutral interviewing'. One conclusion, then, is that much more research is needed into the social and interactional nature of the research interview itself. Despite its ubiquity it has remained surprisingly under studied.

Our second conclusion is that although qualitative interviews are treated as relatively easy to perform (students, for example, often perform open-ended interviews with almost no training) they are very hard to do well. On top of this they are hard to analyse and even harder to analyse well (for example, students, who seemed to have no trouble conducting the interviews themselves, often report major difficulties in making informative or appropriate analytic inferences from them). For these reasons we propose that interviews are overused in qualitative psychology. At the very least, the set of contingent problems we identified should be attended to. And rather than interviews being the default technique there should be a more careful weighing up of their virtues and limitations, and the precise reasons for their use should be given. Researchers should ask more often and more seriously: are interviews essential?

One reason often given for the use of interview research is that due to the sensitivity of the topic it would be impossible to do the research in any other way. The practicalities and ethics of access to delicate material are complex, of course, however we have found that such arguments are often given without the researchers having tried to get access. The right kind of approach (with the appropriate understanding of the risks and work for all the different parties involved) can be effective in very delicate areas (see Hepburn \& Potter, 2003 and Hepburn, forthcoming, for discussions and some styles of approach). We will end with some comments on the use of naturalistic records for research as an alternative.

\section{Naturalistic Records}

Naturalistic records can include audio and video recordings of conversations in everyday or work settings, records of professional-client interaction, television programmes, documents such as medical records or personal diaries and so on. Although the definition of naturalistic has been a source of some controversy (see, for example, Lynch, 2002; Potter, 2002; Speer, 2002a,b; ten Have, 2002) the criterion used here is that the activity being recorded would have happened as it would have anyway; it is not got up by the researcher, for example by way of an open-ended interview. The records are dubbed naturalistic rather than natural in recognition of a range of potential sources of what would traditionally be called reactivity involved in the recruitment, the recording and so on (for a highly relevant debate on this, see Hammersley, 2003; Speer \& Hutchby, 2003). Nevertheless, they are generated with the aim of avoiding active researcher involvement, even if the full realization of this ideal is often impossible. Note that we are advocating naturalist records as a research topic, much like interviews are research topics, but not suggesting that all researchers should use them in discursive psychology or conversation analysis projects. Such records are 
potentially a live and important source of material for of all of the perspectives listed in Table 1. After all, they are records of people living their lives which is one of the main topics of the enterprise of psychology.

One way of considering the value of naturalistic records it to assess them in relation to the four necessary problems discussed above. We can see that naturalistic records: (1) avoid flooding the interaction with psychology and social science agendas; (2) avoid some of the complex interviewer/interviewee footing complexities; (3) have stake and interest tied to particular relevant practices in the domain under study; (4) avoid cognitivism by collecting material where participants are not required to offer abstract conceptual rumination on some aspect of their lives. These advantages are in addition to more familiar advantages of working with naturalist materials that they (1) throw up novel questions and issues; (2) go beyond familiar limits of memory, attention and perception that underpin peoples' accounts of their practices or the organizations in which they work; (3) get representations and 'cognitions' in action; (4) provide resources for appreciating issues of application (see Potter, 2003, 2004 for overview and discussion of these points).

Our identification of problems with qualitative interviews, then, provides the basis of a more systematic account of the virtues of working with naturalistic records. Such material is not the most appropriate in all cases and qualitative interviews are still likely to be the technique of choice for a range of research issues. Nevertheless, we have tried to lay out some considerations that would at least start to question the perhaps surprising and perhaps unsupportable dominance of the qualitative interview in qualitative research in psychology.

\section{Appendix: Transcription Symbols}

[ ]

$\uparrow \downarrow$

$\rightarrow$

Underlining

CAPITALS

${ }^{\circ} \uparrow \underline{\text { know it, }}{ }^{\circ}$

that's r*ight.
Square brackets mark the start and end of overlapping speech. Position them in alignment where the overlap occurs, as shown below.

Vertical arrows precede marked pitch movement, over and above normal rhythms of speech. They are for marked, hearably significant shifts - and even then, the other symbols (full stops, commas, question marks) mop up most of that. Like with all these symbols, the aim is to capture interactionally significant features, hearable as such to an ordinary listener-especially deviations from a common sense notion of 'neutral' which admittedly has not been well defined.

Side arrows are not transcription features, but draw analytic attention to particular lines of text. Usually positioned to the left of the line.

signals vocal emphasis; the extent of underlining within individual words locates emphasis, but also indicates how heavy it is.

mark speech that is obviously louder than surrounding speech (often occurs when speakers are hearably competing for the floor, raised volume rather than doing contrastive emphasis).

'degree' signs enclose obviously quieter speech (i.e., hearably produced-as quieter, not just someone distant).

Asterisks precede a 'squeaky' vocal delivery.

Numbers in round brackets measure pauses in seconds (in this case, 4 tenths of a second). Place on new line if not assigned to a speaker (i.e after a TRP). 
(.)

$(($ text $))$

she wa::nted

hhh

.hhh

Yeh,

y'know?

Yeh.

bu-u-

>he said<

solid. $==$ We had

heh heh

sto(h)p i(h)t

uh um
A micropause, hearable but too short to measure.

Additional comments from the transcriber, e.g. context or intonation.

Colons show degrees of elongation of the prior sound; the more colons, the more elongation. I use one per syllable-length.

Aspiration (out-breaths); proportionally as for colons.

Inspiration (in-breaths); proportionally as for colons.

'Continuation' marker, speaker has not finished; marked by fall-rise or weak rising intonation, as when enunciating lists.

Question marks signal stronger, 'questioning' intonation, irrespective of grammar.

Periods (full stops) mark falling, stopping intonation ('final contour'), irrespective of grammar, and not necessarily followed by a pause.

hyphens mark a cut-off of the preceding sound.

'greater than' and 'lesser than' signs enclose speeded-up talk. Sometimes used the other way round for slower talk.

'Equals' signs mark the immediate 'latching' of successive talk, whether of one or more speakers, with no interval. Also used as below (lines 3-5), where an unbroken turn has been split between two lines to accommodate another speaker on the transcript page.

Voiced laughter. Can have other symbols added, such as underlinings, pitch movement, extra aspiration, etc.

Laughter within speech is signalled by h's in round brackets.

How to spell 'er' and 'erm' the Jefferson way. (Can be added to, etc.)

\section{References}

Antaki, C. 1999: Assessing quality of life of persons with a learning disability: How setting lower standards may inflate well-being scores. Qualitative Health Research 9, 43754.

Antaki, C. \& Rapley, M. 1996: 'Quality of life' talk: The liberal paradox of psychological testing Discourse and Society 7, 293-316.

Antaki, C. Houtkoop-Steenstra, H. Rapley M. 2000: "Brilliant. Next question...": High-grade assessment sequences in the completion of interactional units Research on Language and Social Interaction 33, 235-62.

Antaki, C., Billig, M., Edwards, D. \& Potter, J. 2003: Discourse analysis means doing analysis: A critique of six analytic shortcomings, Discourse Analysis Online, 1, [http://www.shu.ac.uk/daol/previous/v1/n1/index.htm]. This is reprinted as: Antaki, C., Billig, M., Edwards, D. \& Potter, J. 2003: El Análisis del discurso implaca analizar: Critica de seis atajos analiticos. Athenea Digital, 3, [http://antalya.uab.es/athenea/num3/antaki.pdf]

Baker, C. 2001: Ethnomethodological analyses of interviews. In Gubrium, J.F. \& Holstein, J.A., editors, Handbook of interview research: Context and method. London: Sage. 
Baker, C. 2004: Membership categorization and interview accounts. In Silverman, D., editor, Qualitative research: Theory, method and practice $2^{\text {nd }} E d$. London: Sage.

Billig, M. 1977: The new social psychology and fascism European Journal of Social Psychology 7, 393-432.

Billig, M. 1999: Whose terms? Whose ordinariness? Rhetoric and ideology in conversation analysis Discourse and Society 10: 543-558.

Bowers, J.M. 1988: Review essay: Discourse analysis and social psychology British Journal of Social Psychology, 27, 185-192.

Camic, P.M., Rhodes, J.E. and Yardley, L., editors, 2003, Qualitative research in psychology: Expanding perspectives in methodology and design. Washington: American Psychological Association.

Cicourel, A.V. 1964: Method and measurement in sociology. New York; Free Press.

Cicourel, A.V. 1974: Theory and method in a study of argentine fertility. New York: Wiley.

Clayman, S.E. \& Heritage, J. 2002: The News Interview: Journalists and public figures on the air. Cambridge: Cambridge University Press.

Edwards, D. 1997: Discourse and cognition. London: Sage.

Edwards, D. 2003: Analysing racial discourse: The discursive psychology of mind-world relationships. In H. van den Berg, M. Wetherell \& H. Houtkoop-Steenstra, editors, Analysing race talk: Multidisciplinary approaches to the interview. Cambridge: Cambridge University Press.

Edwards, D. and Potter, J. 1992: Discursive Psychology. London: Sage.

Ensink, T. 2003: The frame analysis of research interviews: Social categorization and footing in interview discourse. In van den Berg, H, Wetherell, M. \& HoutkoopSteenstra, H. Eds: Analyzing race talk: Multidisciplinary approaches to the interview pp. 156-177: Cambridge: Cambridge University Press.

Fontana, A. \& Frey, J.H. 2000: The interview: From structured questions to negotiated text. In Denzin, N.K. \& Lincoln, Y.S., editors, Handbook of qualitative research 2 nd Ed. London; Sage.

Garfinkel, H. 1967: Studies in ethnomethodology. Englewood Cliffs, NJ: Prentice-Hall.

Gilbert, G. N. \& Mulkay, M. 1984: Opening Pandora's box: A sociological analysis of scientists' discourse. Cambridge: Cambridge University Press.

Giorgi, A.P. \& Giorgi, B.M. 2003: The descriptive phenomenological method. In P.M. Camic, J.E. Rhodes and L. Yardley, editors, Qualitative research in psychology: Expanding perspectives in methodology and design. Washington: American Psychological Association.

Goffman, E. 1981: Forms of talk. Oxford: Basil Blackwell.

Gubrium, J and Holstein, A. 2001: From the individual interview to the interview society. In Gubrium, J.F. \& Holstein, J.A., editors, Handbook of interview research: Context and method. London: Sage.

Gubrium, J.F. \& Holstein, J.A. 1997: Active interviewing. In Silverman, D., editor, Qualitative research: Theory, method and practice $2^{\text {nd }} E d$. London: Sage.

Hammersley, M. 2003: 'Analytics' are no substitute for methodology: A response to Speer and Hutchby Sociology 37, 339-351.

Henderson, N. 1991: The art of moderating: A blend of basic skills and qualities Quirk's Marketing Research Review, 18, 19-39.

Hepburn, A. 1995: Deconstructing secondary school bullying: A postmodern discourse analysis. Unpublished $\mathrm{PhD}$, Glasgow Caledonian University.

Hepburn, A. 1997a: Teachers and Secondary School Bullying: a postmodern discourse analysis Discourse and Society 8, 27-48.

Hepburn, A. 1997b: Discursive strategies in bullying talk Education and Society 15, 13-31. 
Hepburn, A. 2000: Power lines: Derrida, discursive psychology and the management of accusations of school bullying British Journal of Social Psychology 39, 605-628.

Hepburn, A. forthcoming: Getting closer at a distance: Theory and the contingencies of practice, In Gergen, K., editor, Theory in Action, Special Issue of Theory \& Psychology.

Hepburn, A. \& Brown, S.J. 2001: Teacher Stress and the Management of Accountability Human Relations 546, 531-555.

Hepburn, A. \& Potter, J. 2003: Discourse analytic practice. In Seale, C., Silverman, D., Gubrium J. \& Gobo, G., editors, Qualitative research practice. London; Sage.

Heritage, J.C. 1984: A change-of-state token and aspects of its sequential placement. In Atkinson, J.M. \& Heritage, J.C. editors, Structures of social action: Studies in conversation analysis. Cambridge: Cambridge University Press.

Heritage, J.C. \& Greatbatch, D.L. 1991: On the institutional character of institutional talk: The case of news interviews. In Boden D., \& Zimmerman D.H., editors, Talk and social structure: Studies in ethnomethodology and conversation analysis. Oxford: Polity.

Houtkoop-Steenstra, H. 1995: Meeting both ends: standardization and recipient design in telephone survey interviews. In: ten Have, P., Psathas, G., editors, Situated order: Studies in the social organization of talk and embodied activities. Washington, D.C.: University Press of America.

Houtkoop-Steenstra, H. 1996: Probing behavior of interviewers in the standardized semiopen research interview Quality \& Quantity 30 205-30.

Houtkoop-Steenstra, H. 1997: Being friendly in survey interviews Journal of Pragmatics 28, 591-623.

Hutchby, I., \& Wooffitt, R. 1998: Conversation analysis: Principles, practices and applications. Cambridge: Polity.

Jefferson, G. 1985: An exercise in the transcription and analysis of laughter. In Van Dijk, T., editor, Handbook of discourse analysis, Volume 3. London: Academic Press.

Koole, T. 2003: Affiliation and detachment in interviewer answer receipts. In van den Berg, H, Wetherell, M. \& Houtkoop-Steenstra, H., editors, Analyzing race talk: Multidisciplinary approaches to the interview. Cambridge: Cambridge University Press.

Kvale, S. 1996: InterViews: An introduction to qualitative research interviewing. London: Sage

Lee, Y-J. \& Roth, W-M. 2004, January: Making a scientist: Discursive "doing” of identity and self-presentation during research interviews Forum: Qualitative Social Research [On-line Journal] 51, Art. 12. Available at: http://www.qualitative-research.net/fqstexte/1-04/1-04leeroth-e.htm

Leudar, I. \& Antaki, C. 1996a: Discourse participation, reported speech and research practices in social psychology Theory \& Psychology 6, 5-29.

Leudar, I. \& Antaki, C. 1996b: Backing footing Theory \& Psychology 6, 41-46.

Lynch, M. 2002: From naturally occurring data to naturally organized ordinary activities: Comment on Speer Discourse Studies 4, 531-537.

Marlaire, C. \& Maynard, D. 1990: Standardized testing as an interactional phenomenon, Sociology of Education 63, 83-101.

Maynard, D.W., N.C. Schaeffer 1997: Keeping the gate: declinations of the request to participate in a telephone survey interview Sociological Methods \& Research 26, 3479. 
Maynard, D.W., N.C. Schaeffer 2000: Toward a sociology of social scientific knowledge: Survey research and ethnomethodology's asymmetric alternates Social Studies of Science 30, 323-70.

Mischler, E. 1986: Research interviewing: Context and narrative. Harvard.

Myers, G. 1998: Displaying opinions: Topics and disagreement in focus groups Language in Society 27, 85-111.

Myers, G. 2004: Matters of opinion: Talking about public ideas. Cambridge: Cambridge University Press.

Myers, G. \& Macnaghten, P. 1999: Can focus groups be analysed as talk? In Barbour, R.S. \& Kitzinger, J., editors, Developing focus group research. London: Sage.

Poland, B.D. 2001: Transcription quality. In Gubrium, J.F. \& Holstein, J.A., editors, Handbook of interview research: Context and method. London: Sage.

Pomerantz, A.M. 1984: Agreeing and disagreeing with assessments: Some features of preferred/dispreferred turn shapes. In Atkinson, J.M., \& J. Heritage, J.C., editors, Structures of social action: Studies in conversation analysis pp. 57-101: Cambridge: Cambridge University Press.

Pomerantz, A.M. \& Zemple, A. 2003: Perspectives and frameworks in interviewers' queries. In van den Berg, H., Wetherell M. \& Houtkoop-Steenstra, H., editors, Analysing race talk: Multidisciplinary approaches to the interview. Cambridge: Cambridge University Press.

Potter, J. 1996: Right and wrong footing Theory and Psychology 6, 31-9.

Potter, J. 2002: Two kinds of natural Discourse Studies 4, 539-542.

Potter, J. 2003: Discourse analysis and discursive psychology. In P.M. Camic, J.E. Rhodes and L. Yardley Eds: Qualitative research in psychology: Expanding perspectives in methodology and design pp. 73-94: Washington: American Psychological Association.

Potter, J. (2004). Discourse analysis. In Hardy M. \& Bryman, A., editors, editors, Handbook of Data Analysis. London; Sage.

Potter, J. and Edwards, D. 1990: Nigel Lawson's Tent: Discourse analysis, attribution theory, and the social psychology of fact European Journal of Social Psychology 20, 24-40.

Potter, J. \& Edwards, D. 2001: Discursive social psychology. In Robinson W. P. \& Giles H., editors, The new handbook of language and social psychology. London; John Wiley \& Sons Ltd.

Potter, J. and Mulkay, M. 1985: Scientists' interview talk: Interviews as a technique for revealing participants' interpretative practices. In Brenner, M. Brown J. \& Canter, D., editors, The research interview: Uses and approaches. London: Academic Press.

Potter, J. \& Puchta, C. forthcoming: The power of the POBA - Psychological language and social research practice. In Hepburn A. \& Wiggins S., editors, Discursive Research in Practice: New Approaches to Psychology and Interaction. Cambridge: Cambridge University Press.

Potter, J. and Wetherell, M. 1987: Discourse and Social Psychology: Beyond Attitudes and Behaviour. London: Sage.

Potter, J. and Wetherell, M. 1995: Discourse analysis. In Smith, J. Harré R. and van Langenhove, L., editors, Rethinking methods in psychology. London: Sage.

Puchta, C. \& Potter, J. 1999: Asking elaborate questions: Focus groups and the management of spontaneity Journal of Sociolinguistics 3, 314-35.

Puchta, C. \& Potter, J. 2002: Manufacturing individual opinions: Market research focus groups and the discursive psychology of attitudes British Journal of Social Psychology 41, 345-363.

Puchta, C. \& Potter, J. 2004: Focus group practice. London; Sage. 
Puchta, C., Potter, J. \& Wolff, F. in press: Repeat receipts: A device for generating visible data in market research focus groups Qualitative Research.

Rapley, T. 2001: The artfulness of open-ended interviewing : some considerations on analysing interviews Qualitative Research 1, 303-24.

Rapley, M. \& Antaki, C. 1996: A conversation analysis of the 'acquiescence' of people with learning difficulties Journal of Community and Applied Social Psychology 6, 207227.

Sacks, H. 1992: Lectures on conversation. Vols. I \& II, edited by G. Jefferson. Oxford: Basil Blackwell.

Schegloff, E.A. 1999: Discourse, pragmatics, conversation, analysis Discourse Studies 1, 405-36.

Silverman, D. 2001: Interpreting qualitative data: Methods for analysing talk, text and interaction. London: Sage.

Smith, J.A., editor, 2003: Qualitative psychology: A practical guide to research methods. London; Sage.

Speer, S.A. 2002a: 'Natural' and 'contrived' data: A sustainable distinction? Discourse Studies 4, 511-525.

Speer, S.A. 2002b: Transcending the 'natural'/'contrived' distinction: A rejoinder to ten Have, Lynch and Potter Discourse Studies 4, 543-548.

Speer, S.A. \& Hutchby, I. 2003: From ethics to analytics: Aspects of participants: orientations to the presence and relevance of recording devices' Sociology 37, 315337.

Suchman, L. \& Jordan, B. 1990: Interactional troubles in face-to-face survey interviews Journal of the American Statistical Association 85, 232-241.

ten Have, P. 1998: Doing conversation analysis: A practical guide. London; Sage.

ten Have, P. 2002: Ontology or methodology? Comments on Speer's 'natural' and 'contrived' data: A sustainable distinction? Discourse Studies 4, 527-530.

ten Have, P. 2004: Understanding qualitative research and ethnomethodology. London: Sage.

van den Berg, H, Wetherell, M. \& Houtkoop-Steenstra, H., editors, 2003: Analyzing race talk: Multidisciplinary approaches to the interview. Cambridge: Cambridge University Press.

Warren, C.A.B. 2001: Qualitative interviewing. In Gubrium, J.F. \& Holstein, J.A., editors, Handbook of interview research: Context and method. London: Sage.

Watson, D.R. 2004: Ethnomethodology and textual analysis. In Silverman, D., editor, Qualitative Research: Theory, method and practice $2^{\text {nd }}$ Ed.: London; Sage.

Wetherell, M. and Potter, J. 1988: Discourse analysis and the identification of interpretative repertoires. In Antaki, C, editor, Analysing Lay Explanation: A Case Book. London: Sage.

Widdicombe, S. \& Wooffitt, R. 1995: The language of youth subcultures: Social identity in action. Hemel Hempstead, UK: Harvester/Wheatsheaf.

Wilkinson, S. 2000: Women with breast cancer talking causes: Comparing content, biographical and discursive analyses Feminism \& Psychology 10, 431-460.

Willig, C. 2001: Introducing qualitative research in psychology: Adventures in theory and method. Buckingham: Open University Press. 
Table 1: Psychological perspective, object of study and technique of data generation.

\begin{tabular}{lll}
\hline Perspective & Object of study & $\begin{array}{l}\text { Technique of Data } \\
\text { Generation }\end{array}$ \\
\hline Ethnography & Cultures, rituals, groupings & Interviews \\
Phenomenology & Experience, consciousness & Interviews \\
$\begin{array}{l}\text { Psychoanalysis } \\
\text { Narrative psychology }\end{array}$ & The unconscious & Interviews \\
$\begin{array}{l}\text { Grounded theory } \\
\text { Discourse analysis and life stories }\end{array}$ & Highly varied & Interviews \\
discursive psychology & Talk and texts & Interviews \\
\hline
\end{tabular}


Table 2: Conversational features missed from the orthographic transcript

\begin{tabular}{ll}
\hline Feature & Example \\
\hline Emphasis (underlining) & stressed \\
Closing (full stop) intonation & stressed. \\
Continuing (comma) intonation & situations, \\
Overlaps lined up with square brackets & {$[$ and ] } \\
& {$[$ YEah. ] } \\
Pause lengths timed in seconds & $(0.4)$ \\
Elevated pitch & $\uparrow$ well \\
Elevated volume (capitals) & YEAH \\
Lowered volume (enclosed in ${ }^{\circ} \circ$ ) & ${ }_{\mathrm{kids}}^{\circ}$ \\
Elongated sound (colons) & Er::m \\
Speeded up (enclosed in $><$ ) & $>\mathrm{not}$ always in the< \\
One turn 'latches' onto another with & Er: $:=$ \\
no discernible pause & $=\mathrm{Mm}$. \\
Outbreath & $\mathrm{hh}$ \\
Laughter particle & $\mathrm{huh}$ \\
\hline
\end{tabular}

